Res Pública Revista de Historia de las Ideas Políticas

ISSN: 1131-558X

http://dx.doi.org/10.5209/rpub.70464

\title{
A. Lamar Schweyer, Ensayos sobre poética y política, edición y prólogo de Gerardo Muñoz, Leiden, Bokeh, 2018, 268 pp.
}

En la historia muchos nombres son olvidados, tal vez incluso la historia no sea más que el olvido selectivo de unos y el recuerdo de otros. La obra que aquí se presenta se propone invertir esta historia recuperando a uno de los olvidados, un filósofo y ensayista cubano que vivió entre 1902 y 1942 cuyo nombre fue Alberto Lamar Schweyer.

Si alguien se preguntaba por la relevancia de traer al recuerdo presente esta figura, Gerardo Muñoz, prologuista y editor de esta compilación de textos, se encarga de explicarlo a lo largo de la excelente introducción en la que no sólo presenta, sino que contextualiza y analiza la persona y su obra, proponiendo una lectura crítica y fiel que no pasa por alto sus tendencias políticas menos populares a la luz del posterior desarrollo del siglo XX.

En las primeras páginas de la introducción encontramos ya uno de los motivos, sino el más importante, de la pertinencia de una obra como esta: "Nuestra hipótesis es que la mirada del reaccionario nos ayuda a pensar la crisis de lo político tal y como ocurría en el período de entreguerras, y que posteriormente influiría en las agendas culturales y las miradas intelectuales ante el fenómeno de la técnica" (11) ${ }^{1}$. Esta hipótesis define fielmente la aportación que los escritos de Lamar pueden hacer en la actualidad. Si bien no se trata de tomar las reflexiones que aquí se presentan como claves para entender nuestro presente, sí que ayudan a comprender un periodo histórico confuso, doloroso y determinante para todo el desarrollo del siglo pasado. Desde esta intuición se erige la figura de Lamar como uno de tantos reaccionarios y que, sin embargo, gracias al estilo y la erudición de la que hace gala en estos textos, representa claramente una postura histórica que en ocasiones ha sido menospreciada a la hora de indagar en las causas y consecuencias de la crisis del periodo de entreguerras.

Una de las particularidades que resaltan en la lectura de los textos del cubano es la intrínseca relación que guardan sus reflexiones estéticas con las políticas; dando un nuevo sentido a la frase de Walter Benjamin "la estetización de la política o la politización del arte", podría decirse que en el pensador cubano operan ambas consignas a un mismo tiempo, adquiriendo el arte y en concreto la literatura y la poesía un papel fundamental para la reflexión política. De esta manera, sitúa a Tolstoi como el profeta de la revolución rusa y su, a sus ojos, desastroso resultado: "fue el iniciado y el apóstol de las

Todas las citas pertenecen a la obra que se presenta en esta reseña. nuevas doctrinas y sobre él debe caer gran parte de la responsabilidad en la gran catástrofe que lleva a Rusia camino del abismo" (131).

En la relación entre literatura y política convergen además las principales influencias o arcanos de Alberto Lamar. En los textos que componen la obra pueden distinguirse tres aspectos que marcan y dirigen las preocupaciones del autor. Se trata de su difícil relación con el futurismo, la reflexión en torno a la revolución rusa y la influencia palpable y explícita de la filosofía de Nietzsche.

En primer lugar, en su diagnóstico de la crisis vivida tras la Gran Guerra en todo el mundo, y con especial atención, como no podía ser de otra manera, a la situación política de Cuba y de centro y Sudamérica en general, Lamar observa un paralelismo con la crisis acaecida tras el Romanticismo que tuvo como reacción el Realismo. En ambos momentos lo que ocurre es una honda decepción ante los brutales hechos que impiden ya imaginar un porvenir. "La humanidad, cansada de ver desplomar sus sueños bellos, quiere realidad. Por obra de los tiempos, los filósofos pasarán a ser poetas, o los poetas se tornarán en filósofos. Y la clase que quede atrás morirá pronto. Los sueños del mañana serán positivos como lo es la filosofía de hoy. Es inútil que los últimos románticos se esfuercen en mantener la supremacía del ensueño sobre la realidad. Caerán ellos por ley eterna" (86).

Es en este contexto de crisis absoluta donde el futurismo encuentra su lugar. En este aspecto, de nuevo se mezclan las reflexiones estéticas y las políticas, que encuentran en Nietzsche el hilo conductor de un ámbito a otro. Es por ello que para el pensador cubano el futurismo está insuflado de la filosofía nietzscheana y tiene, además, un corolario práctico-político. Leemos así el siguiente fragmento: "En el futurismo hay el mismo entusiasmo por el porvenir, el mismo desdén por los ídolos, la misma visión real, el mismo amor por la máquina y la fuerza que en el amargo meditativo que Nietzsche hizo pasar por la vida, detestando el nostálgico claro de luna, el sentimentalismo de las viejas canciones y soñando sólo con el heroísmo cruel e injusto de su fiebre conquistadora" (80). No resulta ya extraño, que la plasmación política que guían estas palabras sea la de la dictadura y la fuerte crítica a la democracia, por eso en la introducción ya se avisa de que "el poema del futuro constaba con una forma concreta en el registro político: la dictadura soberana como modelo para un recomienzo político en América Latina" (16). 
Si continuamos el camino que vincula a Nietzsche con el proyecto político de la dictadura encontraremos en la idea del super hombre la clave para la interpretación de Lamar. Hay que insistir en que Lamar lee a Nietzsche desde unas coordenadas muy concretas, y también que lee al Nietzsche que en ese momento estaba disponible, esto es, un Nietzsche incompleto y tergiversado en muchos pasajes. Esta precaución permite comprender fragmentos como el siguiente: "A Nietzsche no le interesa la sociedad como tal, ni el individuo con serlo, es decir, todo individuo, sino únicamente aquellos en que el tipo humano adquiere una máxima potencialidad, un más alto grado cultural, una más determinada capacidad intelectual. Así la sociedad queda en su concepto reducida a pretexto para el advenimiento de esos hombres superiores, y la humanidad a un medio en que se desenvolverán las actividades de esos individuos (...) ¿Egoísmo? Nadie habrá de negarlo. Como derivada de la propia vida de la filosofía niestzscheana es en esencia egoísta" (143).

Esta concepción de la excelencia individual, acompañada de lo que él llama "biología de la democracia" dan lugar a un pequeño texto que cabe resaltar hoy día titulado "El error de la democracia", en este pequeño texto Lamar expone provocativamente cómo a su parecer la democracia no es el régimen adecuado en América. Desde este presupuesto argumenta lo siguiente: "La teoría general del Estado, la teoría del sufragio, el equilibrio de los poderes, la reducción del Gobierno a ser representación no soberana, que América no ha conocido, se deriva de esa fatalidad biológica que, a su vez, cambió esos valores teóricos por valores prácticos: el Estado-teoría, a ineficacia del sufragio, el predominio del Poder Ejecutivo, y el Gobierno soberano encarnado en el dictador o el tirano" (165), y un poco más adelante concluye: "Oponiéndose a esa falsa representación popular el predominio del Ejecutivo es, como hemos dicho, una necesidad. Caudillo o cacique, electo por las armas o por los comicios, el Presidente encarna más directamente la representación de las mayorías; al menos, de las minorías activas en política. Es la justificación científica de la dictadura en América" (167)

Ante estas palabras escritas en 1926 es inevitable preguntarse qué respuesta da el pensador ante la dictadura nazi. No hace falta esperar ya que el libro recoge también fragmentos políticos escritos durante el nazismo donde podemos leer lo siguiente: "La dictadura no es un mal. La dictadura es el único sistema de gobierno en momentos de peligro nacional, cuando no se pueden perder horas en polémicas porque el enemigo toca la puerta" (255). A la luz de estas declaraciones no resulta extraño que Gerardo Muñoz dedique gran parte de su estudio introductorio a explicitar las semejanzas con Carl Schmitt, un paralelismo que enriquece la figura del reaccionario de la primera mitad del siglo XX.

Para concluir, la obra resulta una oportunidad para acercarse a un tipo de pensador muy concreto, el pensador reaccionario del periodo de entreguerras, que además cuenta con la particularidad geográfica y política de pertenecer a la dictadura cubana de Gerardo Machado y de vivir la Revolución del Treinta. Esta experiencia gana profundidad e interés al ser expresada desde una perspectiva estética que permite al autor enriquecer sus escritos.

Paula Sánchez Mayor 